\title{
The Use of Weibull Statistics in Mechanical Testing of Brittle Dental Materials
}

\author{
Wan Mohd Azhar b. IBRAHIM ${ }^{1}$ and J. F McCABE ${ }^{2}$
}

(Received 2 November 1992 and accepted 7 April 1993)

Key words: Weibull statistics, mechanical testing, dental material

\begin{abstract}
The mean strength that has traditionally been taken as a measurement of the strength of a material does not reflect the true strength, and therefore it cannot be used as a design parameter. This explains why many brittle materials fail at unpredictable stress, either below or above the mean strength. By using Weibull statistics, the prediction and assessment of strength can be made more sensibly. The performance of a material can be predicted by considering a stress at a lower level of failure probability.
\end{abstract}

\section{Overview}

If failure probability is plotted against stress to give the strength of a material, the true strength is thought to lie in the upper part of the distribution i. e. on the dotted part of the curve (Fig. 1). The value of stresses that have been measured in mechanical testing are distributed along this curve, at points below the true strength. Particularly for brittle materials, these stresses are caused by flaws in the test specimen.

The mean value that has been taken as a measurement of the strength of any material may only reflect the strength of approximately $50 \%$ failure probability if Weibull statistics are used as a method of measurement. This is not the true strength of the material, as has been stated by IBRAHIM $^{[1]}$. This differs from the case of the height of a man or woman, or the density of a material length, for example, where the mean value may be taken as the true value.

Because the mean strength does not reflect the true strength of a material, it cannot be used as a design parameter. This may explain why many brittle materials fail at an unpredictable stress, either below or above the mean strength.

Figure 2 is a representation of the results obtained from mechanical testing of a brittle material. Curves A and B represent materials A and B, respectively. Material B has a mean strength higher than that of material A, but at stress $\mathrm{X}$, material A will perform better. At a lower probability of failure, it will be stronger than material $B$, even though the mean strength of material B is higher than that of material A. This is another reason why "mean strength" is not a suitable parameter for representing the strength or performance of brittle materials. Therefore to assess the performance of a material, it is necessary to investigate stresses at a lower level of probability. IBRAHIM ${ }^{[1]}$ showed that the stress at any probability of failure predicted by a normal distribution is not reliable, and that the performance of the material cannot be assessed accurately. In this respect, prediction and assessment using Weibull statistics have been proved to be more reasonable and reliable.

The weibull distribution equation was originally proposed by WEIBULL ${ }^{[2]}$. The basic form of the Weibull distribution equation, which gives the relationship between probability of failure $\left(\mathrm{P}_{\mathrm{f}}\right)$ and stress $(\sigma)$, is shown in equation 1. This is a modified form of the Weibull equation used

1 Faculty of Dentistry, University of Malaya, 59100 Kuala Lumpur, Malaysia

2 The Dental School, Flamlington Place, Newcastle upon Tyne, NE2 4BW, United Kingdom

To whom all correspondence should be addressed: Dr. Wan Mohd Azhar IBRAHIM, Department of Prosthetics, Faculty

of Dentistry, University of Malaya, 59100 Kuala Lumpur, MALAYSIA 
by MCCABE AND CARRicK ${ }^{[3]}$ and McCABE AND WALlS ${ }^{[4]}$ :

$$
\mathrm{P}_{\mathrm{f}}=1-\exp \left[-\left(\frac{\sigma-\sigma \mathrm{u}}{\sigma \mathrm{o}}\right) \mathrm{m}\right] \quad[1]
$$

where $\sigma \mathrm{u}, \sigma \mathrm{o}$ and $\mathrm{m}$ are constants. These parameters of the above equation are defined as follows:

(a) $\sigma \mathrm{u}$ is known as the threshold stress. It is a constant and denotes the stress at which the failure probability approaches zero.

(b) $\mathrm{m}$ is known as the Weibull modulus. It has important practical implications, and is a measure of the variability of the quantity $(\sigma-\sigma \mathrm{u})$. It has been given a physical meaning by JAYATILAKA AND TRUSTRUM ${ }^{[5]}$, as characterizing the brittleness of a material. A higher value of $\mathrm{m}$ indicates less scatter or close grouping of fracture stress data, and a lower value represents a large scatter of fracture points. For example (Fig. 2), if a material A has a Weibull modulus of 10 and another material $\mathrm{B}$ has a value of 100 , then material $\mathrm{A}$ is much more brittle than material B, or in other words, material B is much more ductile. Physically, this means that the data obtained from material A are more scattered than material $\mathrm{B}$. In a normal distribution, this degree of data scattering reflects the standard deviation.

(c) The parameter $\sigma o$ is difficult to visualize, and is normally referred to as a normalizing parameter.

(d) The probability of failure $\left(P_{f}\right)$ or survival probability $\left(P_{s}\right)$ for each specimen is calculated from the equations

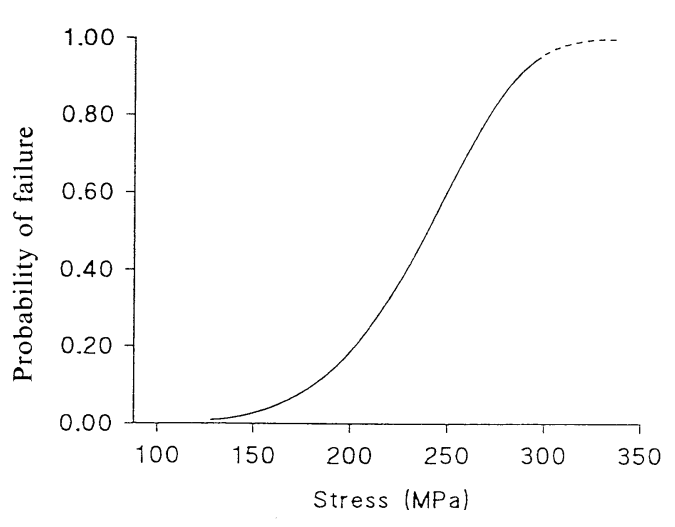

Fig. 1 A Typical Weibull distribution curve.

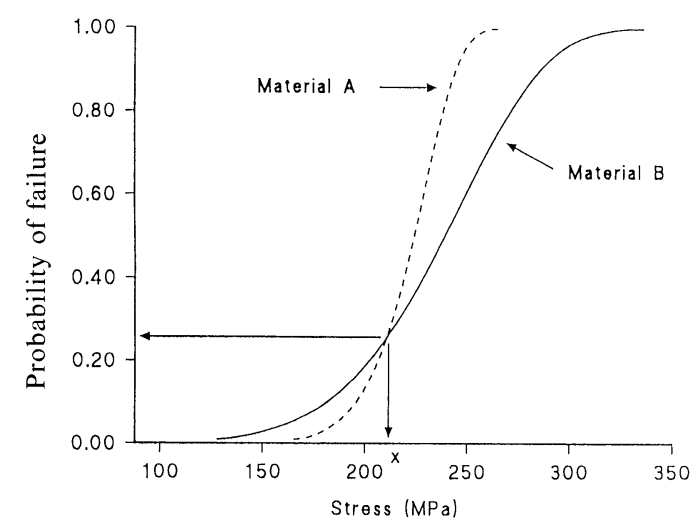

Fig. 2 Comparison between the strengths of two materials.

and

$$
\mathrm{P}_{\mathrm{f}}=\frac{\mathrm{n}}{\mathrm{N}+1}
$$

$$
P_{\mathrm{s}}=1-\mathbf{P}_{\mathrm{f}} \quad[3],
$$

where $\mathrm{N}$ is the total number of specimens and ' $\mathrm{n}$ ' is the ranking number of the specimen. Specimens are ranked in ascending order, where the weakest specimen is given a rank 1 and the strongest rank $\mathrm{N}$.

MCCABE AND CARricK ${ }^{[3]}$ showed that the Weibull equation 'fits' the data obtained from compressive and diametral tensile tests. They also stated that the fracture data from the compressive and the diametral strength test have a better 'fit' to the Weibull distribution function than the flexural strength test data.

In designing an experiment to determine the Weibull Modulus, $\mathrm{m}$, of a brittle material, the investigator must decide how many specimens are to be used. The standard error of the estimate 
is inversely proportional to the square root of the sample size, $\mathrm{N}$. Therefore the number must be increased by a factor of four to decrease the standard error by half.

TRUSTRUM AND JAYATILAKA ${ }^{[6]}$ suggested that the least squares method needs a sample size of about forty when the survival probability ${ }^{[2]}$ is used. KAMIYA AND KAMIGAITO ${ }^{[7]}$ also found from their studies that at least forty or more specimens are required to give an estimated value of the Weibull modulus close to the 'true' value of $\mathrm{m}$.

MCCABE AND CARRICK ${ }^{[3]}$ found that the correlation coefficient obtained from Weibull analysis is good when a large number of specimens, about sixty to seventy, are used. However in another study, MCCABE AND WALLS ${ }^{[4]}$ suggested that at least thirty or more specimens should be used in order to get meaningful results. This finding agrees well with the work of TRUSTRUM AND JAYATILAKA ${ }^{[6]}$ and KAMiYA AND Kamigaito ${ }^{[7]}$.

Not many investigators have used the Weibull distribution function proposed by WEIBULL ${ }^{[2]}$ to analyze the difference in the strengths of brittle materials at failure. Some workers merely applied the Weibull distribution function to the tensile strength of the materials, since the function was originally proposed for tensile failure. However, MCCABE AND CARRICK ${ }^{[3]}$ showed that the function will also 'fit' the data from compressive and diametral compressive strength tests. They also stated that the fracture data from compressive and diametral strength tests 'fit' the Weibull distribution function better than flexural strength test data.

Other investigators ${ }^{[5,8-11]}$ considered that the data from flexural strength tests 'fit' a more complex Weibull equation. However IBRAHIм ${ }^{[1]}$ showed that flexural strength data reasonably 'fit' the equation.

Figures 3 and 4 show the Weibull curves for results of compressive tests on Occlusin (I. C. I., England). A summary of the results of Weibull analysis is shown in Tables 1 and 2.

Figure 3 and Table 1 illustrate the effect of specimen size on strength. For every test, thirty cylindrical specimens $4 \mathrm{~mm}, 5 \mathrm{~mm}$ and $6 \mathrm{~mm}$ in diameter and $6 \mathrm{~mm}$ long were prepared in a split steel mold. The specimens were stored in distilled water for 7 days before being subjected to a compressive force at a cross-head speed of $0.5 \mathrm{~mm} / \mathrm{min}$ using an Instron (Model 1195).

The variation in the value of the Weibull modulus evident in Table 1 indicates that the degree of brittleness of the specimen differs. It seems that the degree of brittleness increases with the size (volume) of the specimen.

It has also been shown by normal statistics that the value of the deviation coefficient increases with specimen size. A larger value of deviation reflects a greater degree of data scatter.

The mean strength of a more brittle specimen is higher than that of a less brittle specimen. This is one of the characteristics of a brittle material. If the mean strength is taken as a design parameter for brittle materials, this may be misleading, since a brittle material may fail at a stress lower than the mean strength. When stress at a lower level is calculated using normal statistics, the value of stress at a lower level is not markedly different from the mean strength. This is evident in Table 1 , where the stresses at $1 \%$ and $0.01 \%$ are not very different from the mean strength. This means that not even $1 \%$ of specimens will fail under a stress of $210 \mathrm{MPa}$. This seems to be unrealistic when compared with what is actually experienced with brittle materials. However, this is not the case for Weibull statistics. The value of stress at a lower level of probability is very different from the mean strength or characteristic strength. Using Weibull statistics, it can be shown that brittle materials will fail at a level of stress lower than the mean strength. For example, at a stress of $150 \mathrm{MPa}, 1 \%$ of specimens $5 \mathrm{~mm}$ in diameter and $6 \mathrm{~mm}$ long will fail.

By using stress at a lower level of probability as a design criterion, it can be seen from Table 1 that the performance of specimens $6 \mathrm{~mm}$ in diameter and $6 \mathrm{~mm}$ long is the most unreliable, even though their mean strength is higher than that for other specimen sizes. This is because the probability of failure at a lower stress is greater than for the others. It can be said that the strength of a large cavity filling is lower than that for a small cavity filling at a lower level of 


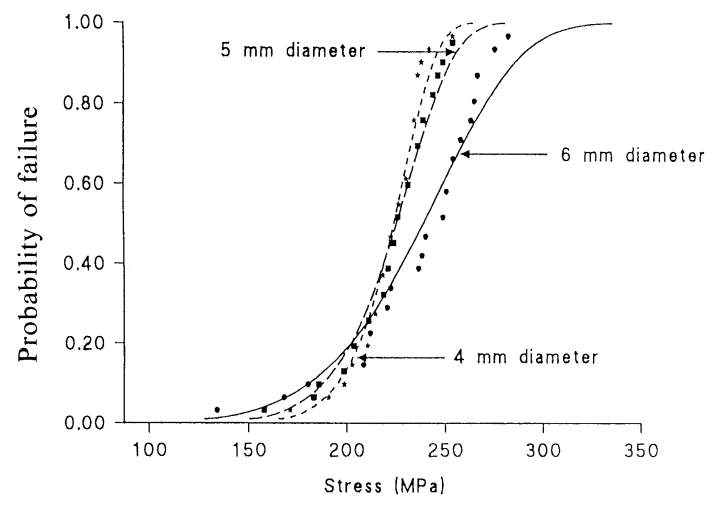

Fig. 3 Weibull curves for specimens of various sizes $(6 \mathrm{~mm}$ long), which were tested at a cross-head speed of $0.5 \mathrm{~mm} / \mathrm{min}$.

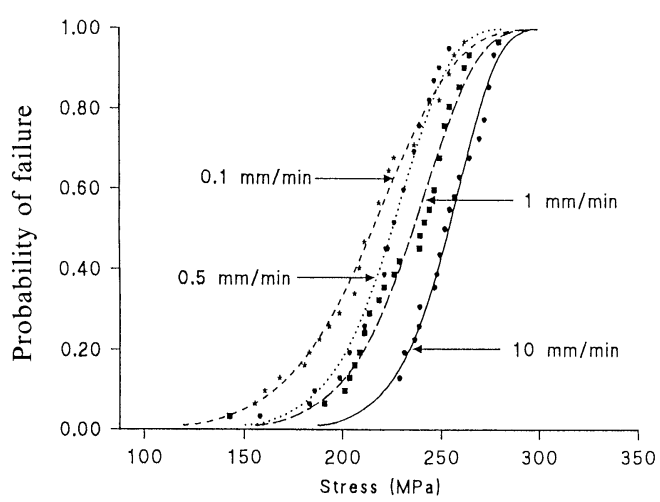

Fig. 4 Weibull distribution curves for specimens $5 \mathrm{~mm}$ in diameter and $6 \mathrm{~mm}$ long, which were tested at various cross-head speeds.

Table 1 Summary of Weibull analysis-Compressive strength of Occlusin for specimens* of various diameters $(6 \mathrm{~mm}$ long) which were tested at a cross-head speed $0.5 \mathrm{~mm} / \mathrm{min}$

\begin{tabular}{|c|c|c|c|}
\hline Diameter $(\mathrm{mm})$ & 4.0 & 5.0 & 6.0 \\
\hline Weibull modulus & 13.8 & 10.4 & 6.8 \\
\hline Characteristic strength $^{+}$ & 230.3 & 233.8 & 252.6 \\
\hline Standard error of modulus & 0.49 & 0.33 & 0.35 \\
\hline Coeff. of correlation & 0.97 & 0.97 & 0.93 \\
\hline Mean strength $^{+}$ & 222.2 & 223.2 & 236.1 \\
\hline Deviation coefficient $(\%)$ & 7.5 & 9.9 & 14.0 \\
\hline \multicolumn{4}{|l|}{ Stress $^{+}$at failure probability } \\
\hline \multirow[t]{2}{*}{$0.01 \%$} & 118.2 & 96.4 & 65.20 \\
\hline & 210.9 & 208.3 & 213.8 \\
\hline \multirow[t]{2}{*}{$1 \%$} & 165.0 & 150.2 & 127.9 \\
\hline & 215.1 & 213.8 & 22.01 \\
\hline \multirow{2}{*}{$\begin{array}{c}\text {-Weibull } \\
\text { Normal }\end{array}$} & 257.3 & 270.8 & 316.7 \\
\hline & 233.5 & 238.1 & 258.4 \\
\hline
\end{tabular}

+ unit in $\mathrm{MPa}$

* Specimens were stored in distilled water for 7 days at $37^{\circ} \mathrm{C}$ and at $100 \%$ humidity prior to testing. One-way analysis of variance - significant difference between strength and specimen size $(\mathrm{p}<0.05)$.

failure probability. This may be because the probability of flaws per unit volume is higher in a large specimen than in a small one. Therefore the use of Occlusin as a filling material in a large cavity should be restricted to lower-stress areas.

Figure 4 and Table 2 illustrate the effect of cross-head speed on the compressive strength of Occlusin. A total of 120 cylindrical specimens $5 \mathrm{~mm}$ in diameter and $6 \mathrm{~mm}$ long were prepared in the same way as described previously. For each cross-head speed, thirty specimens were tested.

Table 2 shows that the brittleness of the material varies according to the cross-head speed. The Weibull modulus decreases as the cross-head speed decreases, and a great variation in the value of stress is noted at $0.01 \%$ or $1 \%$. This shows that the cross-head speed of a testing machine affects the strength of a material. The value of stress at a lower failure probability decreases as the cross-head speed decreases. This shows that the cause of failure of a brittle material is not primarily impact or sudden load. For example, the stress from an impact load of less than 150 $\mathrm{MPa}$ will cause only $0.01 \%$ of specimens to fail. However, the same stress under the influence of 
Table 2 Summary of Weibull analysis-Compressive strength of Occlusin tested at various cross-head speeds for Specimens $5 \mathrm{~mm}$ in diameter and $6 \mathrm{~mm}$ long*

\begin{tabular}{|c|c|c|c|c|}
\hline Cross-head Speed $(\mathrm{mm} / \mathrm{min})$ & 10.0 & 1.0 & 0.5 & 0.1 \\
\hline Weibull modulus & 13.9 & 10.1 & 10.4 & 7.2 \\
\hline Characteristic strength $^{+}$ & 261.0 & 245.1 & 233.8 & 227.1 \\
\hline Standard error of modulus & 0.40 & 0.33 & 0.33 & 0.13 \\
\hline Coeff. of correlation & 0.98 & 0.97 & 0.97 & 0.99 \\
\hline Mean strength ${ }^{+}$ & 248.1 & 232.7 & 223.2 & 213.1 \\
\hline Deviation coefficient (\%) & 12.2 & 11.9 & 9.9 & 14.6 \\
\hline \multicolumn{5}{|l|}{ Stress $^{+}$at failure probability } \\
\hline \multirow[t]{2}{*}{$0.01 \%$} & 134.5 & 98.5 & 96.4 & 63.2 \\
\hline & 227.6 & 214.0 & 208.3 & 192.1 \\
\hline \multirow[t]{2}{*}{$1 \%$} & 187.3 & 155.3 & 150.2 & 119.4 \\
\hline & 235.2 & 220.9 & 213.8 & 199.9 \\
\hline \multirow{2}{*}{$\begin{array}{r}\text {-Weibull } \\
\text { Normal }\end{array}$} & 291.4 & 285.2 & 270.8 & 281.1 \\
\hline & 268.5 & 251.4 & 238.1 & 234.1 \\
\hline
\end{tabular}

* Specimens were stored in distilled water for 7 days at $37^{\circ} \mathrm{C}$ and at $100 \%$ humidity prior to testing. One-way analysis of variance-very highly significant difference between strength and cross-head speed $(\mathrm{P}<0.001)$.

+ unit in $\mathrm{MPa}$.

creep may cause $1 \%$ of specimens to fail. Failure of this kind in the mouth may be minimized by avoiding biting on nuts or other foods that are hard enough to break.

Therefore, it can be concluded that the examples given in Figs. 3 and 4 and also in Tables 1 and 2 show that the compressive strength of Occlusin varies according to specimen size and cross-head speed. This overview has also shown that the Weibull distribution is a far better form of analysis than a normal distribution for describing the performance of brittle materials. Weibull statistics allow a better understanding of the behavior of materials. The significance of the use of Weibull statistics in dental materials science is that it assures the use of correct scientific methods to assess the performance of materials, allowing stronger and more durable restorative materials to be developed.

\section{References}

[1] Ibrahim, W. M. A.: Strength parameters of some brittle dental materials, Weibull analysis, Ph. D. Thesis, University of Newcastle Upon Tyne, United Kingdom, 1991

[2] Weibull, W.: A statistical distribution function of wide applicability, J. Appl. Mechan., 18, 293-295, 1951

[3] MCCABE, J. F. and CARrick, T. E.: A statistical approach to mechanical testing of dental materials, Dent. Mater., 2, 139-142, 1986

[4] McCabe, J. F. and Walls, A. W. G.: The treatment of results for tensile bond strength testing, J. Dent., 14, $165-168,1986$

[5] Jayatilaka, A. D. S. and Trustrum, K.: Statistical approach to brittle fracture, J. Mater. Sci., 12, 1426-1428, 1977

[6] Trustrum, K. and Jayatilaka, A. D. S.: On estimating the Weibull modulus for a brittle material, J. Mater. Sci., 14, 1080-1084, 1979

[7] Kamiya, I. and Kamigaito, O.: Estimation of Weibull parameters by omission of some data in sample, $J$. Mater. Sci., 19, 4021-4025, 1984

[8] Davies, D. G. S.: Design in brittle materials with special reference to silicon nitride, Fulmer Research Institute, Research report R275/5, 1971

[9] Jones, D. W., Jones, P. A. and Wilson, H. J.: The relationship between transverse strength and testing methods for dental ceramic, J. Dent., 1, 85-91, 1972

[10] Davies, D. G. S.: The statistical approach to engineering design in ceramics, Proc. Br. Ceram. Soc., 22, 429-452, 1973

[11] Stannley, P., Fessler, H. and Sivill, A. D.: An engineer's approach to prediction of failure probability of brittle components, Proc. Br. Ceram. Soc., 22, 453-458, 1973 